\title{
OS BENEFÍCIOS E DIFICULDADES NA GESTÃO DA QUALIDADE DE VIDA NO TRABALHO
}

Luiz Carlos Marque Carrera

Doutor em Engenharia de Materiais pela Universidade de Ciência e Tecnologia Montpellier II - França - Instituto Brasileiro de Geografia e Estatística - IBGE

Roberto Kern Gomes Mestre em Administração de Empresas pela ESAG/UDESC. Doutorando em Engenharia e Gestão do Conhecimento pela UFSC Universidade Federal de Santa Catarina

Patrícia Del Castanhel Claumann Mestranda em Engenharia e Gestão do Conhecimento pela UFSC - Universidade Federal de Santa Catarina - UFSC

Eduardo Zanardi Mestrando em Engenharia de Produção pela Universidade Federal Tecnológica do Paraná - UTFPR

\section{RESUMO}

Vive-se atualmente a Era do Conhecimento, em que as organizações necessitam investir de maneira sistemática em seus recursos humanos, essencialmente pelo fato de que são as pessoas quem podem fazer a diferença nas organizações. Neste contexto, a Qualidade de Vida no Trabalho (QVT) adquire cada vez mais protagonismo no seio destas organizações visando conciliar expectativas pessoais aos objetivos e metas organizacionais. Neste contexto, este trabalho faz uma abordagem ampla sobre o atual estado de conhecimento da QVT, começando pela síntese de suas conceituações e do relato de seu desenvolvimento histórico, passando pela análise crítica de seus principais modelos, com ênfase no modelo de QVT de Walton, um dos mais difundidos no desenvolvimento dos Programas de Qualidade de Vida nas organizações. Assim, através de uma pesquisa bibliográfica, pretende-se identificar quais são estas principais dificuldades e quais os benefícios de se implantar um programa de qualidade de vida no trabalho. Finalmente, conclui-se que o sucesso destes programas se deve principalmente à incorporação de seus principais elementos à cultura organizacional da empresa.

Palavras-Chave: Comportamento Organizacional. Qualidade de Vida no Trabalho. Satisfação no Trabalho.

\section{ABSTRACT}

We are now living the Knowledge Age, where organizations need to invest systematically in its human resources, first of all becouse it is people who can make 
difference in organizations. In this context, Quality of Work Life (QWL) acquires increasing function within these organizations aimed at reconciling personal expectations to organizational goals and objectives. Thus, this paper makes a comprehensive approach on the current state of knowledge of QWT, beginning with the synthesis of its concepts and shows its historical development, through critical analysis of its key models, with emphasis on the QWT model of Walton, one of the most widespread in the development of the Quality of Life Programs in organizations. Thus, through a literature search, we intend to identify what these major difficulties and the benefits of deploying a quality program of work life. Finally, it is concluded that the success of these programs is mainly due to the incorporation of its key elements to the organizational culture of the company.

Keywords: Organizational Behavior. Quality of Work Life. Job Satisfaction.

\section{INTRODUÇÃO}

Vive-se atualmente o período que Domenico De Masi (2000) e Alvin Toffler (1970), cada um em seu tempo, denominaram ser a era pós-industrial. Este momento recebeu também de Chiavenato (1999) a nomenclatura de era da informação. Na era pós-industrial ou da informação, o conhecimento é a base estratégica e competitiva das organizações, em lugar das máquinas do período industrial. Assim, mais modernamente, diz-se que a atual era é, de fato, a era do conhecimento. Nessa era do conhecimento, o principal ativo são as pessoas, detentoras do conhecimento, que é o principal ativo agregador de valor das organizações. Assim, a Qualidade de Vida no Trabalho (QVT) é um dos temas a que se tem dado muita importância, devido às mudanças velozes e constantes que esta nova era tem trazido ao mundo do trabalho e devido à importância que os trabalhadores adquiriram na matriz de prioridades das organizações.

Para que se alcance a almejada competitividade é necessário, portanto, que os indivíduos estejam satisfeitos com suas atividades no ambiente de trabalho. Robbins (2005, p. 61) define que a satisfação com o trabalho refere-se "a atitude geral de uma pessoa em relação ao trabalho que ela realiza". O Autor descreve ainda que "uma pessoa que tem alto nível de satisfação com seu trabalho, apresenta atitudes positivas com relação a ele". 


\section{ADMINISTRAÇÃO DE EMPRESAS EM REVISTA}

Funcionários satisfeitos e felizes em seu ambiente de trabalho produzem mais, sendo que a satisfação no trabalho tem efeitos positivos sobre a queda do absenteísmo, rotatividade e cidadania organizacionais. Além disso, há evidências que a satisfação do cliente pode ser afetada pela satisfação dos funcionários, sobretudo no setor de serviços, uma vez que funcionários satisfeitos com o seu trabalho tendem a atender melhor aos seus clientes (ROBBINS, 2005).

Neste contexto, a melhoria das condições de vida e da saúde tem sido um tema de crescente importância, já que tem impacto direto e indireto na produtividade das pessoas, e os resultados obtidos pelas organizações. Por isso, tão importante quanto as condições de vida das comunidades são as práticas desenvolvidas pelas empresas, já que é nas empresas que o ser humano desenvolve uma parte muito significativa de sua vida: o trabalho.

Com essas afirmações, parece restar claro a necessidade de se investir em qualidade de vida no trabalho, tendo em vista que esta traz consigo o aumento da satisfação do trabalhador com o ambiente em que está desempenhando suas atividades laborativas (OLIVEIRA; LIMONGI-FRANÇA, 2005).

Todavia, existem tanto dificuldades como benefícios na aplicação das políticas de QVT e uma organização. Assim, este artigo tem o objetivo de responder justamente quais são estas principais dificuldades e quais os benefícios de se implantar programas de qualidade de vida no trabalho.

\section{FUNDAMENTAÇÃO TEÓRICA}

\subsection{HISTÓRICO DA QUALIDADE DE VIDA NO TRABALHO}

O século $X X$ trouxe alterações profundas na percepção da importância que o trabalho tem na vida das pessoas. Com o desenvolvimento da era da industrialização, as atividades desempenhadas ficaram monótonas e repetitivas, o que refletiu nos colaboradores uma diminuição da motivação, um aumento dos problemas físicos, um acréscimo dos acidentes de trabalho e erros na produção. Esta monotonia foi satirizada na obra "Tempos Modernos" de Charles Chaplin. 
A escola humanística de George Elton Mayo, ainda na década de 1930, surgiu como resposta à mecanização do trabalhador e pretendia melhorar as relações sociais e as condições do trabalho. Assim, foi com esses estudos, e para dar resposta ao modelo Taylorista, que se desenvolveram investigações sobre o ambiente de trabalho, tais como influência da luminosidade na produtividade, inserção de intervalos entre as jornadas, melhoria das condições do ambiente etc... Assim, podem-se atribuir a Mayo os primeiros estudos diretamente relacionados com o conceito de Qualidade de Vida no Trabalho (GUEDES, 2009).

Essa primeira fase do movimento sobre a Qualidade de Vida no Trabalho perdurou até a década de 1970, quando, em função da preocupação com questões econômicas, como a crise energética (crise do petróleo) e a crescente inflação, o interesse pela QVT, erroneamente, ficou em segundo plano. O entendimento dos empresários à época era que a necessidade de sobrevivência das empresas era o principal, em detrimento dos interesses dos funcionários, que passaram a ter uma importância secundária (TOLFO; PICCININI, 2001).

No Brasil a preocupação com QVT surgiu mais tarde, mas agora em consonância com a preocupação acerca da competitividade das empresas. Em um contexto de maior abertura para a importação de produtos estrangeiros, ocorrido na década de 1990 e na esteira dos programas de qualidade, os empresários brasileiros perceberam que a competitividade passaria pelos programas de geração de qualidade de vida e satisfação dos trabalhadores (TOLFO; PICCININI, 2001).

Atualmente, a saúde não é vista meramente como a ausência de doença, mas, sim, determinada também por influências externas variadas do meio ambiente, além do estilo de vida dos indivíduos e o equilíbrio entre fatores externos e internos do ser humano. Acredita-se que o equilíbrio está relacionado à harmonia entre todos os âmbitos vitais que circundam o trabalhador. Assim, importante se faz que as empresas tenham preocupação em fomentar atividades que promovam a coexistência pacífica entre as metas organizacionais e as atividades pessoais do trabalhador, dando-lhe tempo para reaver suas energias com atividades diversas, como esportes, lazer e convívio familiar. Estas ações estão diretamente ligadas à qualidade de vida.

Neste contexto, o termo Qualidade de Vida (QV) está sendo, também, inserido 


\section{ADMINISTRAÇÃO DE EMPRESAS EM REVISTA}

no ambiente de trabalho, local onde os indivíduos dedicam grande parte de seu tempo (ALVES, 2011).

Também é importante salientar que a crescente preocupação com a qualidade de vida no trabalho está intimamente ligada com o mercado competitivo. Este mercado, cada vez mais exigente e movido pelos avanços tecnológicos, redefine o trabalhador como sendo a verdadeira potência. Assim, a motivação e o comprometimento são os combustíveis dessa potência. Portanto, a promoção de Qualidade de Vida nas empresas vem se tornando a maneira essencial para manterse a motivação e o comprometimento. (ALVES, 2011).

\subsection{CONCEITUAÇÕES}

Pode-se afirmar que, ao longo do tempo, a definição da QVT sofreu significativas modificações. Inicialmente, era vista como uma variável em que o importante era compreender como as condições ambientais do trabalho influenciavam o desempenho do colaborador. Essa visão se justifica devido ao momento histórico em que foi desenvolvida, qual seja, o período da administração científica, situado no início do século $\mathrm{XX}$, quando imperava o conceito mecanicista e taylorista do homo economicus ${ }^{1}$. Nos anos 70 , consoante com as teorias comportamentais de Herzberg, Maslow, McGregor e outros, a QVT passou a ser uma abordagem que tinha como princípio a satisfação do indivíduo. Já nos anos 80 , foi considerado um movimento que apresentava designações como a "democratização do trabalho" ou a "humanização dos trabalhadores" contra os modelos de trabalho existentes (GUEDES, 2009).

Apesar de que, ao longo do tempo, a definição do conceito QVT tenha sofrido consideráveis modificações, isso não significa que atualmente exista uma definição clara e objetiva do conceito. Assim, normalmente, os autores adotam a definição que consideram melhor se adaptar ao contexto em que estão inseridos. Entretanto, parece haver certo consenso de que a QVT é um conceito que lida com o bem-estar dos

1 Conceito mecanicista criado por Taylor no início do século XX, segundo o qual o homem era movido somente por motivações econômicas. 
trabalhadores e difere de satisfação profissional, uma vez que esta é consequência daquela (GUEDES, 2009).

Não obstante, necessário se faz apresentar alguns conceitos importantes sobre QVT. Neste sentido, segundo Albuquerque e Limongi-França (1998, apud Oliveira e Limongi-França, 2005), Qualidade de Vida no Trabalho pode ser entendida como:

um conjunto de ações de uma empresa que envolve diagnóstico e implantação de melhorias e inovações gerenciais, tecnológicas e estruturais dentro e fora do ambiente de trabalho, visando propiciar condições plenas de desenvolvimento humano para e durante a realização do trabalho.

Fernandes (1996, p. 132) é mais específico ao conceituar QVT, pois a define como um processo pelo qual:

uma organização tenta revelar o potencial criativo de seu pessoal, envolvendo-os em decisões que afetam suas vidas no trabalho. Uma característica marcante do processo é que seus objetivos não são simplesmente extrínsecos, focando melhora da produtividade e eficiência em si; eles também são intrínsecos no que diz respeito ao que o trabalhador vê como fins de autorrealização e auto-engrandecimento.

Castro (2002, apud Weimar, 2009, p. 471), por sua vez, acredita que

a motivação é um dos principais fatores que influenciam na qualidade de vida no trabalho das pessoas de uma empresa. A motivação busca a felicidade individual, influenciando diretamente na eficácia das relações através de dois grandes vetores; a motivação interna e a motivação externa, sendo que ambas visam bem atender seus colaboradores fazendo com que produzam mais, gerando mais lucros para a empresa.

Por fim, apresenta-se o conceito de Chiavenato (2004, p. 448) que define a qualidade de vida no trabalho como sendo:

[...] uma ferramenta que implica profundo respeito pelas pessoas. Para alcançar níveis elevados de qualidade e produtividade, as organizações precisam de pessoas motivadas, que participem ativamente nos trabalhos que executam e que sejam adequadamente recompensadas pelas suas contribuições.

Assim, sem a pretensão de esgotar o assunto, percebe-se que os conceitos giram comumente acerca da busca pela satisfação dos funcionários e a consequente resposta em termos de produtividade. 


\title{
ADMINISTRAÇÃO DE EMPRESAS EM REVISTA
}

\subsection{A GESTÃO DOS PROGRAMAS DE QUALIDADE DE VIDA NO TRABALHO (GQVT)}

Alguns autores definem a QVT como uma metodologia. Neste contexto, Rodrigues (2006, p. 5) afirma que

a qualidade de vida é uma metodologia que envolve pessoas, trabalho e organização, tendo como objetivo a busca do bem-estar, a participação, a integração do trabalhador aos objetivos organizacionais e a eficácia organizacional, através da melhor qualidade e maior produtividade.

É muito importante que a gestão de pessoas das organizações esteja atenta desde o momento da contratação dos funcionários, de modo a identificar e selecionar os profissionais que se encaixem na cultura organizacional. Assim, haverá a garantia de que estes profissionais estarão em consonância em termos de comportamento e expectativa (GEHRINGER, 2013). Ao longo do tempo é importante ainda que a empresa monitore se estas condições continuam a existir na relação empresaempregado.

Ainda acerca da gestão da qualidade de vida no trabalho, encontram-se diversas abordagens na literatura, mas, segundo Rodrigues (2012, p. 51).

\begin{abstract}
todas elas tem em comum a tendência de alinhar as expectativas do colaborador com os objetivos da organização, ou seja, a QVT tem como uma de suas principais bases de apoio os aspectos culturais da organização, buscando o comprometimento dos colaboradores às diretrizes e norteadores culturais.
\end{abstract}

A figura 1 ilustra esta abordagem.

\section{Figura 1: Abordagem metodológica de QVT}

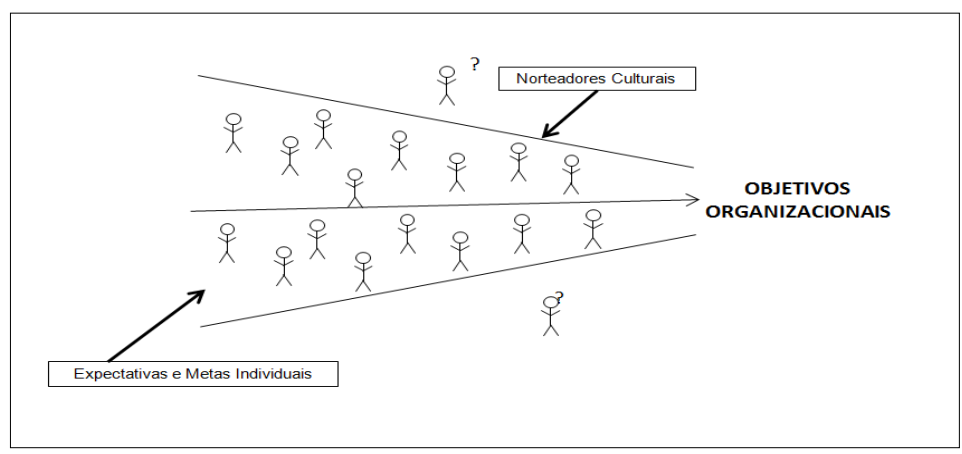

Fonte: adaptado de Rodrigues (2012). 
Rodrigues (2012) explica que os trabalhadores que se encontram fora dos limites estabelecidos pela organização estão na "marginalidade", caracterizada pela condição de o colaborador não aceitar as causas ou objetivos organizacionais. Isto ocorre basicamente por duas situações, o colaborador mudou em relação ao que ele era quando foi contratado, ou a empresa se encontra em processo de adequação da cultura organizacional e de seus valores, sendo este menos comum, pois a cultura organizacional é algo que foi sendo moldada ao longo dos anos (GEHRINGER, 2013).

Diante da "marginalidade", "a organização deve tentar ressocializar o colaborador aos novos valores ou postura organizacional. Em caso de insucesso, o colaborador deve ser realocado ou eliminado do sistema", explica Rodrigues (2012, p. $51)$.

De maneira a evitar situações extremas como a eliminação do colaborador do sistema, é importante que as empresas tenham uma gestão da QVT bem estruturada. Rodrigues (2012, p. 52) ressalta que "a QVT apresenta como fatores diretivos os valores e as crenças organizacionais e que o nível ideal de QVT está associado ao ponto ótimo do trinômio motivação/desempenho/satisfação".

Para que os programas de gestão da qualidade de vida no trabalho possam ter sucesso e serem aprimorado, é necessário que se implantem sistemas de avaliação destes programas. Assim, o tópico a seguir tratará deste tema.

\subsubsection{Modelos para Avaliação da QVT}

Chiavenato (1999), apud Rossi (2011, p. 6), afirma que é possível encontrar diversos modelos para avaliar a QVT, sendo considerados os três mais importantes: Modelo de QVT de Nadler e Lawdler; Modelo de QVT de Hackman e Oldhan e Modelo de QVT de Walton. Segundo Pacheco (2012, p 104), o modelo de Walton é um dos mais utilizados para avaliação da QVT, "desde que atenda aos interesses da empresa", desta forma este será destacado neste artigo.

De acordo com Walton (apud CHIAVENATO, 1999), são oito os fatores que influenciam a QVT, o primeiro é referente à compensação justa e adequada, onde é 


\section{ADMINISTRAÇÃO DE EMPRESAS EM REVISTA}

observada se a remuneração do colaborador está condizente com o cargo no qual ocupa e às atividades que realiza e se há um equilíbrio com os demais salários praticados na empresa e com os valores pagos em outras empresas. O segundo trata as condições de segurança e saúde no trabalho, onde são considerados a jornada de trabalho e o ambiente físico, observando se o mesmo é adequado à saúde do trabalhador e se não o expõe a perigos. Em seguida é abordada a utilização e desenvolvimento da capacidade, que, segundo Pacheco (2012 p. 104):

refere-se às possibilidades de o trabalhador satisfazer suas necessidades de utilização das habilidades e dos conhecimentos, de desenvolver sua autonomia, autocontrole e de obter informações sobre o processo total do trabalho, bem como de retroinformações quanto ao seu desempenho".

O quarto fator, oportunidade de crescimento e segurança, é referente à possibilidade de carreiras, o crescimento e desenvolvimento profissional e a estabilidade ou segurança no emprego. Em seguida observa-se a integração social na organização, onde um bom nível, segundo Pacheco (2012 p. 104), é medido pela "ausência de diferenças hierárquicas demasiadamente marcantes, apoio mútuo, franqueza interpessoal e ausência de preconceito são pontos fundamentais para o estabelecimento de um bom nível de integração social nas empresas".

O fator seguinte, Garantias constitucionais, "estabelece as normas e regras da organização, direitos e deveres do trabalhador e recursos contra decisões arbitrárias é necessário para que se estabeleça um clima de democracia", Pacheco (2012 p. 105). O sétimo fator, trabalho e o espaço total de vida, trabalha o equilíbrio entre vida pessoal e profissional. O último aborda a relevância social da vida no trabalho, traduzido na imagem da empresa e na responsabilidade social por seus produtos, serviços e colaboradores. O quadro a seguir ilustra os 8 fatores e suas dimensões.

\section{Quadro 1. Modelo de QVT de Walton}

\begin{tabular}{|l|l|}
\hline Fatores de QVT & Dimensões \\
\hline 1. Compensação justa e adequada & 1. Renda adequada ao trabalho \\
& $\begin{array}{l}\text { 2. Equidade interna } \\
\text { 3. Equidade externa }\end{array}$ \\
\hline 2. Condições de segurança e saúde no trabalho & 4. Jornada de trabalho
\end{tabular}




\section{ADMINISTRAÇÃO DE EMPRESAS EM REVISTA}

\begin{tabular}{|c|c|}
\hline & 5. Ambiente Físico \\
\hline 3. Utilização e desenvolvimento da capacidade & $\begin{array}{l}\text { 6. Autonomia } \\
\text { 7. Significado da tarefa } \\
\text { 8. Identidade da tarefa } \\
\text { 9. Variedade de habilidades } \\
\text { 10. Retroação e retroinformação }\end{array}$ \\
\hline 4. Oportunidade de crescimento e segurança & $\begin{array}{l}\text { 11. Possibilidades de carreiras } \\
\text { 12. Crescimento profissional } \\
\text { 13. Segurança do emprego }\end{array}$ \\
\hline 5. Integração social na organização & $\begin{array}{l}\text { 14. Igualdade de oportunidades } \\
\text { 15. Relacionamentos interpessoais e grupais } \\
\text { 16. Senso comunitário }\end{array}$ \\
\hline 6. Garantias constitucionais & $\begin{array}{l}\text { 17. Respeito às leis e direitos trabalhistas } \\
\text { 18. Privacidade pessoal } \\
\text { 19. Liberdade de expressão } \\
\text { 20. Normas e rotinas claras da organização }\end{array}$ \\
\hline 7. Trabalho e espaço total de vida & 21. Papel balanceado do trabalho na vida pessoal \\
\hline 8. Relevância social da vida no trabalho & $\begin{array}{l}\text { 22. Imagem da empresa } \\
\text { 23. Responsabilidade social pelos produtos/serviços } \\
\text { 24. Responsabilidade social pelos empregados }\end{array}$ \\
\hline
\end{tabular}

Fonte: Chiavenato, 1999, apud Rossi (2011, p. 6).

Rodrigues (2012 p. 53), falando acerca do sucesso dos programas de QVT, relata a importância da participação dos funcionários, quando afirma que "o sucesso dos processos de melhoria está diretamente associado às ações e posturas dos colaboradores, não existindo programa de qualidade bem-sucedido onde não há a preocupação efetiva pela qualidade de vida dos colaboradores".

Já Chiavenato (1999, apud Rossi 2011, p. 7), lembra que os programas de QVT não precisam necessariamente demandar muitos recursos econômicos, semelhantes ao que são implantados por grandes empresas. Para o autor, há diversas atividades de caráter orientativo, que se referem "a qualidade da alimentação, exercícios físicos, dietas alimentares, controle de pressão arterial, entre outras, bem como garantir a manutenção do clima organizacional". Assim, todas estas atividades podem gerar benefícios para a qualidade de vida dos trabalhadores. 


\title{
ADMINISTRAÇÃO DE EMPRESAS EM REVISTA
}

Limongi-França (2005, p. 9) tem sua posição calcada no fato de que cabe ao setor de Recursos Humanos a tarefa de levar a cabo as atividades de QVT. O autor pontua que as ações de QVT são desenvolvidas principalmente pelo departamento de Recursos Humanos, mas que "todas as ações que a empresa e os empregados desenvolvem na busca da integração biopsicossocial e do controle dos fatores de riscos ocupacionais estão ligadas a gestão da qualidade de vida no trabalho". Os principais programas de QVT acabam tendo foco em atividades associativas e esportivas; eventos de turismo e cultura; atendimento à família; processos de seleção e avaliação de desempenho, carreira, remuneração e programas participativos, que exercem sem dúvida influência sobre a qualidade de vida dos funcionários; medidas ergonômicas e de cuidados com a alimentação.

Independente de quem levará a cabo os programas de QVT e quais atividades eles abrangerão, é necessário que se tenha consciência dos passos a serem tomados nesta direção. Assim, Rodrigues (2012, p. 53) ressalta que,

\begin{abstract}
para melhorar o nível de QVT no trabalho, o primeiro passo é identificar quais são as categorias de análise que não estão apresentando posições satisfatórias. Como segunda ação é preciso identificar as categorias de análise que apresentam posições críticas e criar programas específicos contextualizados à realidade da organização.
\end{abstract}

Finalmente, analisando os autores estudados para este artigo, pode-se afirmar que, se os programas de QVT obtiverem sucesso, este sucesso se refletirá na competitividade da empresa. Isto se deve ao fato de que ela conseguirá reter talentos. Assim, um dos objetivos ocultos das empresas que desenvolvem programas de QVT é justamente a retenção de talentos e segundo Rossi (2011, p. 8), conseguem isso ofertando "condições de trabalho diferenciadas" que resultam na formação de "uma aliança entre os objetivos organizacionais e os objetivos individuais". Portanto, investir em programas de QVT pode ser também uma decisão lucrativa e de grandes benefícios para as organizações.

\subsection{DIFICULDADES NA IMPLANTAÇÃO DE PROGRAMAS DE QUALIDADE DE VIDA NO TRABALHO}


Ainda que se tenham pontuado diversos benefícios que são oriundos da aplicação da QVT nas organizações, é importante salientar que existem situações em que sua implantação é dificultada.

Pode-se afirmar que há alguns aspectos que se configuram com barreiras na implantação de programas de qualidade de vida. Estes estão relacionados principalmente à cultura organizacional, à forma como os processos internos são conduzidos, à política de recursos humanos e ao grau de estreitamento entre a relação colaborador/empresa.

Timossi (2006, p. 5) as dificuldades são relacionadas à aversão que as pessoas têm às mudanças. Para o autor, "muitas vezes essas resistências podem não ser intencionais, e sim uma resposta involuntária à insegurança gerada pelas mudanças que virão". Assim, a maneira como a mudança é apresentada é fundamental para a minimização da resistência, sendo que "não se pode colocar a implementação de um programa ou um novo sistema organizacional como condição imposta, isso poderia levar a um processo inicial de rejeição" TIMOSSI (2006, p. 5)

Lisondo (2005, apud Timossi 2006, p.5), por sua vez, afirma que "as resistências podem ser potencializadas ou amenizadas pela cultura organizacional, pelos modelos de gerenciamento e pelo estilo de liderança, principalmente na relação entre gestores e colaboradores".

Limongi-França (2002, apud Timossi 2006, p. 5) é quem enfatiza a importância da cultura organizacional como fator que pode, inicialmente, ser um dificultador, mas que passa a auxiliar a QVT, ao afirmar que:

quando a valorização da qualidade de vida no trabalho for absorvida pela
cultura da organização, esse mesmo controle comportamental que na
implementação do programa foi um fator gerador de dificuldades e
resistências passa a interagir a favor. Quando a cultura da organização
acredita e acolhe com ênfase e autenticidade o conceito de Qualidade de
Vida no Trabalho que, em última instância, se resume em aliviar o sofrimento
no trabalho, ela deixa menos espaço para as resistências e mais para o
pensamento.

Assim, à luz da teoria estudada, conclui-se que a cultura organizacional deve ser tomada como parceira das iniciativas de implantação de programas de qualidade de vida no trabalho. 


\section{ADMINISTRAÇÃO DE EMPRESAS EM REVISTA}

\section{METODOLOGIA DE PESQUISA E ETAPAS DO TRABALHO}

O presente trabalho tem como objetivo levantar conceitos de qualidade de vida no trabalho, assim como contextualizar o tema ao longo dos anos e mostrar métodos eficazes de gestão de QVT, as dificuldades na implantação e quais são os benefícios para as empresas e para os funcionários em se ter uma gestão de QVT eficaz.

Para alcançar o objetivo proposto neste trabalho, foi utilizada pesquisa qualitativa, com levantamento bibliográfico e de caráter exploratório, que, segundo Castro (2006, apud Zapelini e Zapelini, 2013, p. 78) "representa uma tentativa de conhecer com maior profundidade um problema ou fenômeno, [..] com intuito de "produzir conhecimento". Ainda segundo o autor, neste tipo de pesquisa, "o raciocínio é predominantemente indutivo, permitindo exploração mais livre e aberta do tema da pesquisa" (CASTRO, 2006, apud Zapelini e Zapelini, 2013, p. 78)".

Para o cumprimento dos objetivos propostos por este artigo, sua elaboração foi dividida em seis etapas, quais sejam:

1. Levantamento Histórico da qualidade de vida, com intuito de identificar os primeiros autores que abordaram o tema e em qual contexto;

2. Conceituação de QVT, de acordo com alguns autores como LimongiFrança (2005) e Guedes (2009), através de levantamento bibliográfico visando aprofundamento do tema;

3. Gestão dos Programas de QVT, com intuito de identificar como é gerenciada a QVT nas empresas e que aspectos são pertinentes nesta abordagem;

4. Identificação dos modelos existentes de avaliação da QVT e a escolha do Modelo de Walton, para seu estudo, por ser um dos mais utilizados.

5. Dificuldades na Implantação de Programas de Qualidade de Vida No Trabalho;

6. Considerações finais e conclusões em sobre a importância da QVT nas empresas. 


\section{DISCUSSÃO DOS RESULTADOS}

O que pôde perceber través dos textos estudados para este artigo é que a concepção de qualidade de vida no trabalho teve uma grande mudança no decorrer do último século, passando de um modelo meramente fisiológico, para um modelo que abrange todas as dimensões da existência humana.

As organizações parecem ter percebido que o sucesso da empresa está intimamente ligado ao bem-estar de seus colaboradores, de tal sorte que os programas de implementação da qualidade de vida dos funcionários têm extrapolado as fronteiras do setor de recursos humanos para chegar até a alta direção, responsável pela estratégia e manutenção da cultura empresariais.

Como mencionado anteriormente, a saúde não é mais vista somente como a ausência de doença. O conceito atual de saúde e preconizado pelos ideólogos dos programas de qualidade de vida no trabalho abrange as questões que estão fora da empresa. Assim, para que o funcionário tenha de fato qualidade em sua vida e para que isto se reflita no seu desempenho, é necessário que se tenha uma abordagem sistêmica de suas condições de vida.

Neste contexto, o modelo de Walton inova justamente por trazer para o conceito de qualidade de vida no trabalho as questões de relevância social da vida no trabalho e a integração social na organização, além das já tradicionais preocupações com desenvolvimento do funcionário, suas condições físicas de trabalho, o reconhecimento pelos seus êxitos e as questões legais que envolvem a vida do empregado.

Outra questão importante abordada na literatura estudada é o fato de que é fundamental o envolvimento dos funcionários para o sucesso dos programas de qualidade de vida no trabalho. Isso que dizer que eles têm que entender que o programa visa em primeiro lugar a satisfação de todos. Além disso, os autores também enfatizam que os programas devem estar inseridos na cultura organizacional, condição sine qua non para o seu êxito. 


\section{ADMINISTRAÇÃO DE EMPRESAS EM REVISTA}

Finalmente, ainda sob a luz do que foi estudado, a versão à mudança, inerente à natureza, e a desconfiança dos funcionários são apontadas como principais razões de resistências à implantação dos programas de qualidade de vida no trabalho.

\section{CONSIDERAÇÕES FINAIS}

Os resultados apresentados fazem inferir que o estudo da qualidade de vida no trabalho emergiu de uma preocupação meramente física e ambiental, preconizada no início da teoria das relações humanas, para uma visão holística presente no atual conceito de Qualidade de Vida no Trabalho.

O trabalhador terá maior produtividade e satisfação com o seu trabalho se perceber que a empresa lhe proporciona um ambiente que o valorize também como o ser humano que é, valorização esta que se dá através do reconhecimento que o homem é um ser social e, portanto, deve ter suas relações familiares, de lazer e culturais valorizadas no contexto organizacional.

As empresas, por sua vez, percebem que esta atitude acaba por ter repercussão nos seus resultados, uma vez que de fato os trabalhadores têm ocupado papel de destaque na estratégia competitiva das organizações Modernas.

Por outro lado, percebe-se também que, como grande parte dos programas que trazem algum tipo de mudança organizacional, os programas de Gestão de Qualidade de Vida no trabalho também encontram algumas barreiras. Contudo, percebe-se que estas barreiras surgem quando os programas são inseridos de maneira "top-down" ou ainda em dissonância com a cultura organizacional presente na organização.

Assim, necessário se faz que qualquer programa respeite a cultura organizacional e esteja alinhado com a estratégia da empresa.

\section{REFERÊNCIAS}

ALVES, Everton Fernando. Programas e ações em qualidade de vida no trabalho: possibilidades e limites das organizações.Revista Eletrônica Fafit/facic, Itararé - SP, 


\section{ADMINISTRAÇÃO DE EMPRESAS EM REVISTA}

v. 2, n. 1, p.14-25, 01 jun. 2011. Disponível em: <http://www.fafit.com.br/revista>. Acesso em: 07 abr. 2013.

CHIAVENATO, Idalberto. Gestão de Pessoas: O novo papel dos recursos humanos nas organizações. Rio de Janeiro: Campus, 1999.

, Idalberto. Gestão de Pessoas: Segunda Edição, Totalmente Revisada e Atualizada. 2 ed. Rio de Janeiro: Elsevier, 2004.

DE MASI, Domenico. O Ócio Criativo. Rio de Janeiro: Sextante, 2000.

DETONI, D. (2001). Estratégias de avaliação da qualidade de vida no trabalho: Estudos de Caso em Agroindústrias. Dissertação de Mestrado. Universidade Federal de Santa Catarina.

FERNANDES, E. C. Qualidade de vida no trabalho: como medir para melhorar. 2. ed. Salvador: Casa da Qualidade, 1996.

GEHRINGER, Max, O ambiente de trabalho é filho da cultura da empresa. Mundo Coorporativo: CBN Diário, São Paulo. Disponível em

http://cbn.globoradio.globo.com/comentaristas/max-gehringer/> . Acesso em: 17 mai. 2013.

GUEDES, Simone Cardoso. Relação entre qualidade de vida no trabalho e indicadores de satisfação profissional. 2009. 1 v. Dissertação (Mestrado) - Curso de Psicologia, Faculdade De Psicologia E De Ciências Da Educação, Universidade de Lisboa, Lisboa - Portugal, 2009.

Disponível em: <http://hdl.handle.net/10451/875>. Acesso em: 07 abr. 2013.

OLIVEIRA, Patrícia Morilha de; LIMONGI-FRANÇA, Ana Cristina. AVALIAÇÃO DA GESTÃO DE PROGRAMAS DE QUALIDADE DE VIDA NO TRABALHO. Rae Eletrônica: Fundação Getúlio Vargas, São Paulo, v. 4, n. 1, p.1-21, 01 jul. 2005. Disponível em: <http://rae.fgv.br/eletronica>. Acesso em: 30 mar. 2013.

ROBBINS, Stephen P. Comportamento Organizacional. São Paulo: Person Prentice Hall, 2005.

RODRIGUES, Marcus Vinícius Carvalho. Ações para a Qualidade, 4ํeㄹ. Rio de Janeiro: Editora Elsevier, 2012.

TOFFLER, Alvin. O Choque do Futuro. Rio de Janeiro: Editora Record, 1970. 


\section{ADMINISTRAÇÃO DE EMPRESAS EM REVISTA}

Rossi, D.U.; SCHMENK, A. V.; Moreira, E. C.; Arias, J;.C. Desafios Para Implantar Um Programa De Qualidade De Vida No Trabalho: Um Estudo De Caso Em Uma Indústria Química De Pequeno Porte. In: ENCONTRO NACIONAL DE ENGENHARIA DE PRODUÇÃO, 31, 2011, Belo Horizonte, 2011, p. 4-8.

TIMOSSI, L. da S.; FRANCISCO, A. C. de; MICHALOSKI, A. O; As dificuldades e os fatores culturais no processo de implementação de um programa ergonômico e ginástica laboral em um órgão público federal: um estudo e caso; In: Encontro Nacional de Engenharia de Produção, 8, 2006 Fortaleza, 2006, p. 4-6.

TOLFO, Suzana da Rosa; PICCININI, Valmíria Carolina. As melhores empresas para trabalhar no Brasil e a qualidade de vida no trabalho: disjunções entre a teoria e a prática. Revista de Administração Contemporânea, Curitiba, v. 5, n. 1, p.165-193, 01 abr. 2001. Disponível em: <rac@anpad.org.br>. Acesso em: 30 mar. 2013.

WEIMAR, Paulo Renato; ANDRIETI, Jaqueline. Qualidade de vida no trabalho: estudo de caso na Câmara Municipal de Blumenau. Revista Interdisciplinar Científica Aplicada, Blumenau, v.3, n.4, p.467-487, Sem II 2009. Temática TCC.

ZAPELINI, Marcello B, ZAPELINI, Silvia M. K. Metodologia Científica e da Pesquisa Fean, Faculdade Fean, Florianópolis. Disponível em <www.fean.com.br>. Acesso em: 30 ago. 2014. 